\title{
Prediction of Methane, Water and Ice Properties for Numerical Gas Hydrate Simulations
}

\author{
Şükrü Merey \\ Department of Petroleum and Natural Gas Engineering, Faculty of Engineering, Batman University, Batman, \\ Turkey \\ sukru.merey@batman.edu.tr \\ Received: 3 February 2018 \\ Accepted: 02 April 2018 \\ DOI: $10.18466 /$ cbayarfbe. 389820
}

\begin{abstract}
Gas hydrates are considered as near-future potential energy resources. Due to the lack of gas production data from gas hydrate reservoirs, numerical simulations are very important to make production predictions for both experimental studies and field production trials. Methane and water flow together when gas hydrates dissociate inside the sediments. Hence, many parameters of methane and water such as density, viscosity, enthalpy, internal energy and thermal conductivity should be calculated at different pressure and temperature values during non-isothermal numerical gas production simulations from gas hydrate reservoirs. As a solid phase, ice might exist in the pores due to the endothermic dissociation of gas hydrates. For this reason, water, methane, ice properties as a function of temperature and pressure are estimated by the Matlab codes written in this study: waterprop.m, gasprop.m, and iceprop.m. Density, viscosity, enthalpy, internal energy and thermal conductivity of water and methane calculated with the Matlab codes in this study, National Institute of Standards and Technology were compared, and the reliability of waterprop.m, gasprop.m and iceprop.m was proved.
\end{abstract}

Keywords: Gas hydrates, methane hydrate, methane, water, ice, numerical simulation, equations of states.

\section{Introduction}

Unconventional gas reserves such as shale gas, coalbed methane and gas hydrates have become very important with the decline of conventional gas reserves. Among these reservoirs, the amount of gas in gas hydrate reservoirs is the highest. Since 1970s, many gas hydrate reserve calculations have been made for gas hydrates in marine and permafrost environments by using gas hydrate stability zone thickness, pressure gradient, temperature gradient, salinity, porosity, hydrate saturation, etc. It is considered that even with the conservative estimates, gas hydrate reserves are at least 2 times greater than all conventional gas reservoirs [1].

Figure 1 shows the gas hydrate distribution in the world both in permafrost environment and marine environment. Approximately $99 \%$ of gas hydrates are found in marine sediments and other $1 \%$ of gas hydrates is found in permafrost region. In the last decades, many gas hydrate experimental, numerical, exploration studies and field production trials were conducted [1].

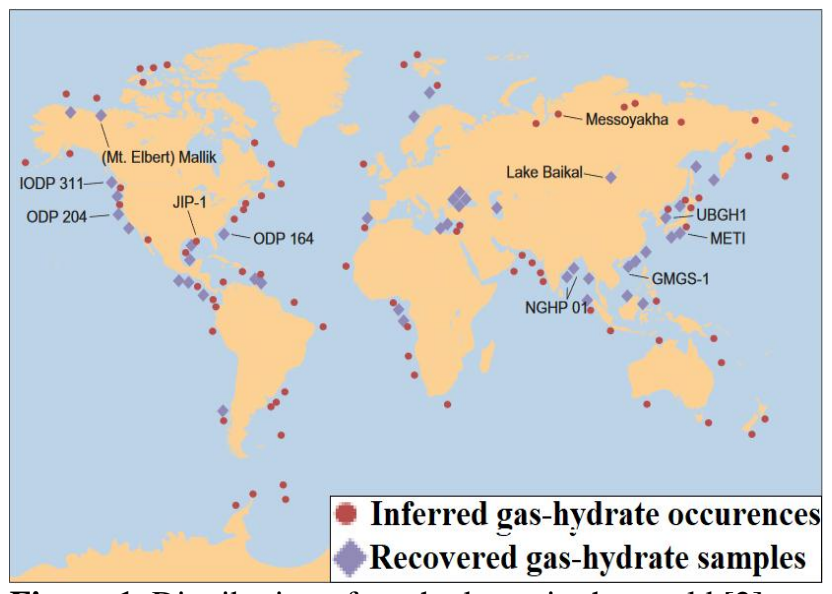

Figure 1. Distribution of gas hydrates in the world [2].

Gas hydrates are ice-like structures that form at low temperature and high pressure conditions. At these conditions, water and gas molecules form gas hydrates with the effect of hydrogen bonds between water molecules and van der Waals forces between gas molecules and water molecules. Thus, gas molecules are trapped inside the cages formed by water molecules [2]. 
Methane $\left(\mathrm{CH}_{4}\right)$, ethane $\left(\mathrm{C}_{2} \mathrm{H}_{6}\right)$, propane $\left(\mathrm{C}_{3} \mathrm{H}_{8}\right)$, i-butane (i$\left.\mathrm{C}_{4} \mathrm{H}_{10}\right)$, carbon dioxide $\left(\mathrm{CO}_{2}\right)$, hydrogen sulfide $\left(\mathrm{H}_{2} \mathrm{~S}\right)$ and other molecules form gas hydrates when these molecules interact with water molecules at high pressures and low temperatures. In nature, although there are mixed gas hydrates formed from gas mixtures including $\mathrm{CH}_{4}, \mathrm{C}_{2} \mathrm{H}_{6}$, $\mathrm{C}_{3} \mathrm{H}_{8}$, etc., it is considered that nearly $99 \%$ of gas hydrates include approximately $100 \%$ of $\mathrm{CH}_{4}$ (biogenic gas) [1]. Figure 2 shows $\mathrm{CH}_{4}$ hydrate equilibrium curve calculated by HEP.m software, predicting gas hydrate properties written by Merey and Sinayuc [3]. Generally, the temperature of $\mathrm{CH}_{4}$ hydrate reservoirs in marine sediments is less than $30^{\circ} \mathrm{C}$ [1].

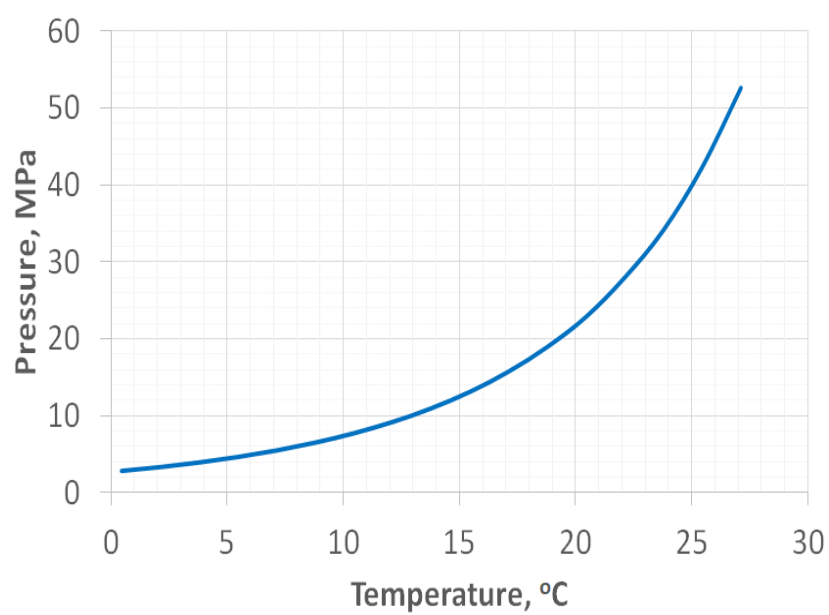

Figure 2. $\mathrm{CH}_{4}$ hydrate equilibrium curve calculated by HEP software [3].

Recently, a few gas production test trials were conducted in Nankai Through Field, Japan (marine sediments), Mallik Field, Canada (permafrost), and Ignik Sikumi Field, Alaska (permafrost). The first depressurization production method in marine sediments was conducted in Nankai Trough, 2013 and 120,000 $\mathrm{m}^{3} \mathrm{CH}_{4}$ was produced in 6 days from gas hydrate sections in this field. Depressurization method is basically to decrease reservoir pressure below gas hydrate equilibrium pressure and after gas hydrate dissociation, free gas and free water are produced via wellbore. In Mallik Field, depressurization method, thermal injection method and combination of these methods were applied [1]. Basically, the aim of thermal injection is to increase temperature by an injection of hot water, steam or microwave heating and destabilize gas hydrates in sediments [2]. As shown in Figure 2, if temperature and pressure of a gas $\left(\mathrm{CH}_{4}\right)$ hydrate reservoir are above $\mathrm{CH}_{4}$ hydrate equilibrium curve, gas hydrates are stable. However, if the chemicals such as methanol, ethylene glycol, etc. are injected into gas hydrate reservoirs, $\mathrm{CH}_{4}$ hydrate equilibrium curve is shifted to left and gas hydrates dissociate. This method is called chemical injection method. Different from these three production methods, $\mathrm{CH}_{4}-\mathrm{CO}_{2}$ swapping method was suggested. Below $10.3^{\circ} \mathrm{C}$, pure $\mathrm{CO}_{2}$ hydrate is much more stable compared to pure $\mathrm{CH}_{4}$ hydrate. Hence, when $\mathrm{CO}_{2}$ is injected into $\mathrm{CH}_{4}$ hydrate reservoirs, $\mathrm{CH}_{4}$ and $\mathrm{CO}_{2}$ gas molecules swap and $\mathrm{CO}_{2}$ is stored in hydrate cages while some $\mathrm{CH}_{4}$ molecules are pushed outside and then they are produced. For better $\mathrm{CH}_{4}$ recovery, $77 \% \mathrm{~N}_{2} / 23 \% \mathrm{CO}_{2}$ gas mixture was injected into $\mathrm{CH}_{4}$ hydrate reservoir at $5.6^{\circ} \mathrm{C}$ in Ignik Sikumi Field, Alaska (permafrost) and $\mathrm{CH}_{4}-\mathrm{CO}_{2} / \mathrm{N}_{2}$ swapping was observed for the first time in this field trial in 2012 [1].

Currently, all available gas hydrate production methods have some advantages and handicaps. For instance, depressurization is considered as the most promising production method because no extra heat inserted since its handicaps are high water production rate, low gas production rate and geomechanical stability problems. Thermal injection is an effective way to dissociate gas hydrates but heat loss, feasibility problems, injection problems and geomechanical stability problems of sediments are the main handicaps of this method. Chemical injection method is not preferred commonly since it is harmful for the environment and expensive. Although $\mathrm{CH}_{4}$ $\mathrm{CO}_{2}$ swapping is advantageous for both $\mathrm{CO}_{2}$ sequestration and geomechanical stability of sediments, this method has injection problems, low replacement rate and risk of pure $\mathrm{CO}_{2}$ hydrate formation [2].

Numerical simulation of gas production from gas hydrates is quite important as in conventional oil and gas reservoirs. One of the handicaps of gas hydrate numerical studies is that there is almost no long term field gas production data from gas hydrate reservoirs and it is difficult to test the success of numerical codes. With gas hydrate experimental data and field-trial project data such as Mallik Field, these gas hydrate numerical codes were improved and tested. Table 1 shows the numerical simulators for gas hydrate production by depressurization, thermal injection and chemical injection. Some of these simulators have ability to model $\mathrm{CH}_{4}-\mathrm{CO}_{2} / \mathrm{N}_{2}$ swapping such as Mix3HydrateResSim, STOMP-HYD-KE, and CMG-Stars [4].

The numerical simulators in Table 1 can model the nonisothermal gas release, phase behavior and flow of fluids and heat under conditions typical of common natural $\mathrm{CH}_{4}$ hydrate deposits in complex geological media at any scale at which Darcy's law is valid by solving the coupled equations of mass and heat balance [5]. 
Table 1. Reservoir Simulation codes used for hydrate reservoirs [4].

\begin{tabular}{|c|c|c|c|}
\hline Name & Owner & Capabilities & $\begin{array}{c}\text { Source } \\
\text { Availability }\end{array}$ \\
\hline $\begin{array}{l}\text { HydrateRes } \\
\text { Sim }\end{array}$ & $\begin{array}{c}\text { Lawrence } \\
\text { Berkeley, } \\
\text { National } \\
\text { Laboratory, } \\
\text { National } \\
\text { Energy } \\
\text { Technology } \\
\text { Laboratory }\end{array}$ & $\begin{array}{c}\text { Kinetics and } \\
\text { Equilibrium } \\
\text { Model }\left(\mathrm{CH}_{4}\right. \\
\text { hydrate })\end{array}$ & $\begin{array}{l}\text { Free Open } \\
\text { Source Code }\end{array}$ \\
\hline CMG Starts & $\begin{array}{l}\text { Computer } \\
\text { Modelling } \\
\text { Group Ltd. }\end{array}$ & $\begin{array}{c}\text { Kinetics and } \\
\text { Equilibrium } \\
\text { Model } \\
\left(\mathrm{CH}_{4} / \mathrm{CO}_{2}\right. \\
\text { hydrates })\end{array}$ & $\begin{array}{l}\text { Commercial } \\
\text { Code }\end{array}$ \\
\hline $\begin{array}{c}\text { MH-21 } \\
\text { HYDRES }\end{array}$ & $\begin{array}{c}\text { National } \\
\text { Institute of } \\
\text { advanced } \\
\text { Industrial } \\
\text { Sciences and } \\
\text { Technology, } \\
\text { Japan }\end{array}$ & $\begin{array}{l}\text { Kinetics and } \\
\text { Equilibrium } \\
\text { Model }\left(\mathrm{CH}_{4}\right. \\
\text { hydrate })\end{array}$ & $\begin{array}{c}\text { Only MH-21 } \\
\text { consortium }\end{array}$ \\
\hline $\begin{array}{c}\text { TOUGH+HY } \\
\text { DRATE }\end{array}$ & $\begin{array}{l}\text { Lawrence } \\
\text { Berkeley } \\
\text { National } \\
\text { Laboratory }\end{array}$ & $\begin{array}{c}\text { Equilibrium } \\
\text { and Kinetics } \\
\text { Model }\left(\mathrm{CH}_{4}\right. \\
\text { hydrate })\end{array}$ & $\begin{array}{c}\text { Free for U.S. } \\
\text { Government, } \\
\text { Collaborator } \\
\text { and Available } \\
\text { for purchase }\end{array}$ \\
\hline $\begin{array}{l}\text { Code from } \\
\text { University of } \\
\text { Houston }\end{array}$ & $\begin{array}{l}\text { University of } \\
\text { Houston }\end{array}$ & $\begin{array}{c}\text { Kinetic } \\
\text { Model }\left(\mathrm{CH}_{4}\right. \\
\text { hydrate })\end{array}$ & Not Available \\
\hline HYRES & $\begin{array}{c}\text { German Sugar, } \\
\text { Umsicht }\end{array}$ & $\begin{array}{c}\text { Kinetic } \\
\text { Model }\left(\mathrm{CH}_{4}\right. \\
\text { hydrate })\end{array}$ & Not Available \\
\hline $\begin{array}{l}\text { STOMP- } \\
\text { HYD-KE }\end{array}$ & $\begin{array}{l}\text { Pacific } \\
\text { Northwest } \\
\text { National } \\
\text { Laboratory }\end{array}$ & $\begin{array}{l}\text { Kinetics and } \\
\text { Equilibrium } \\
\text { Model }\left(\mathrm{CH}_{4-}\right. \\
\mathrm{CO}_{2} \text { mixed } \\
\text { hydrate })\end{array}$ & $\begin{array}{c}\text { Free for U.S. } \\
\text { Government, } \\
\text { Collaborator } \\
\text { and Available } \\
\text { for purchase }\end{array}$ \\
\hline $\begin{array}{l}\text { Mix3Hydrate } \\
\text { ResSim }\end{array}$ & $\begin{array}{l}\text { National } \\
\text { Energy } \\
\text { Technology } \\
\text { Laboratories } \\
\text { (NETL) }\end{array}$ & $\begin{array}{c}\text { Kinetics and } \\
\text { Equilibrium } \\
\text { Model }\left(\mathrm{CH}_{4-}\right. \\
\mathrm{CO}_{2}-\mathrm{N}_{2} \\
\text { mixed } \\
\text { hydrate }) \\
\end{array}$ & Not Available \\
\hline
\end{tabular}

During the simulation of gas and water flow after gas hydrate dissociation, many parameters such as viscosity, density, thermal conductivity, enthalpy, etc. of water, gas and ice should be calculated at different temperatures and pressures. This is because the pressure of gas hydrate reservoir changes with production and also the reservoir temperature changes with the endothermic dissociation of gas hydrates [5]. Even if reservoir temperature is above freezing point of water, during production with depressurization method, reservoir temperature might decrease below freezing point of water with the endothermic dissociation of gas hydrates and ice might form in the pores. For this case, the prediction of ice properties become important.
Formation of ice might increase gas production rate with the latent heat released with ice formation or ice might decrease effective permeability and gas production rate. Hence, the prediction of ice properties is crucial as the prediction of water and $\mathrm{CH}_{4}$ properties. Mostly, the numerical simulators of gas hydrates include four components (hydrate, methane, water, and inhibitor) and four phases (hydrate, gas, aqueous, ice) [5]. Hence, I proposed HEP.m Matlab code predicting gas hydrate properties at different pressures and temperatures and I proved the success of HEP.m code with the article of Merey and Sinayuc [3]. In order to develop numerical gas hydrate simulator for depressurization, thermal and chemical injection, as well as hydrate properties, the properties of water, $\mathrm{CH}_{4}$ and ice at different temperatures and pressures should be calculated. For this reason, in this study, several Matlab codes were written for predicting water, ice and $\mathrm{CH}_{4}$ properties and these codes were integrated with HEP.m [3]. The reliability of these codes were proven in this study.

\section{Materials and Methods}

\subsection{Numerical Simulation of Gas Hydrate Reservoirs}

In order to simulate gas and water production from gas hydrate reservoirs, mass balance equations and Darcy flux equations should be constructed but if the simulation occurs in non-isothermal environment, additionally, heat balance equations should be written for each phases. Dissociation of gas hydrate is endothermic so it should include all mass equations, Darcy flux equations, heat balance equations for each component. The equations used in the hydrate simulators in Table 1 are mostly similar. In order to show the importance of $\mathrm{CH}_{4}$, water and ice properties for these equations, the following formulas used in HydrateResSim simulator from Equation (2.1) to (2.10) are listed [5]:

The continuity equation for component $\mathrm{CH}_{4}(\mathrm{~m})$ can be written as [5]

$$
\begin{gathered}
\frac{\partial\left(\varphi S_{A} \rho_{A} X_{A}^{m}\right)}{\partial t}+\frac{\partial\left(\varphi S_{G} \rho_{G} X_{G}^{m}\right)}{\partial t}+\nabla\left(X_{A}^{m} F_{A}\right)+\nabla\left(X_{G}^{m} F_{G}\right)+ \\
\nabla\left(J_{G}^{m}\right)=X_{A}^{m} q_{A}+X_{G}^{m} q_{G}+n_{\text {weight }}^{m}
\end{gathered}
$$

The continuity equation for component water (w) can be written as [5]:

$$
\begin{gathered}
\frac{\partial\left(\varphi \mathrm{S}_{\mathrm{A}} \rho_{\mathrm{A}} \mathrm{X}_{\mathrm{A}}^{\mathrm{w}}\right)}{\partial \mathrm{t}}+\frac{\partial\left(\varphi \mathrm{S}_{\mathrm{G}} \rho_{\mathrm{G}} \mathrm{X}_{\mathrm{G}}^{\mathrm{w}}\right)}{\partial \mathrm{t}}+\nabla\left(\mathrm{X}_{\mathrm{A}}^{\mathrm{w}} \mathrm{F}_{\mathrm{A}}^{\overrightarrow{\mathrm{A}}}\right)+\nabla\left(\mathrm{X}_{\mathrm{G}}^{\mathrm{w}} \mathrm{F}_{\mathrm{G}}^{\overrightarrow{\mathrm{t}}}\right)+ \\
\nabla\left(\mathrm{J}_{\mathrm{G}}^{\mathrm{w}}\right)=\mathrm{X}_{\mathrm{A}}^{\mathrm{w}} \mathrm{q}_{\mathrm{A}}+\mathrm{X}_{\mathrm{G}}^{\mathrm{w}} \mathrm{q}_{\mathrm{G}}+\dot{\mathrm{n}} \mathrm{M}_{\text {weight }}^{\mathrm{w}}
\end{gathered}
$$

The continuity equation for component hydrate $(\mathrm{h})$ can be written as [5]

$$
\frac{\partial\left(\varphi S_{H} \rho_{H}\right)}{\partial \mathrm{t}}=-\dot{\mathrm{n}} \mathrm{M}_{\mathrm{weight}}^{\mathrm{h}}
$$


The energy balance equation can be written based on the summation of the enthalpy over all phases as [5]:

$$
\begin{array}{r}
\frac{\partial\left((1-\varphi) \rho_{\mathrm{R}} \mathrm{H}_{\mathrm{R}}\right)}{\partial \mathrm{t}}+\frac{\partial\left(\varphi \mathrm{S}_{\mathrm{A}} \rho_{\mathrm{A}} \mathrm{H}_{\mathrm{A}}\right)}{\partial \mathrm{t}}+\frac{\partial\left(\varphi \mathrm{S}_{\mathrm{G}} \rho_{\mathrm{G}} \mathrm{H}_{\mathrm{G}}\right)}{\partial \mathrm{t}}+\frac{\partial\left(\varphi \mathrm{S}_{\mathrm{H}} \rho_{\mathrm{H}} \mathrm{H}_{\mathrm{H}}\right)}{\partial \mathrm{t}}+ \\
\frac{\partial\left(\varphi \mathrm{S}_{\mathrm{I}} \rho_{\mathrm{I}} \mathrm{H}_{\mathrm{I}}\right)}{\partial \mathrm{t}}-\nabla\left(\mathrm{K}_{\mathrm{ave}} \nabla \mathrm{T}\right)+\nabla\left(\mathrm{f}_{\sigma} \sigma_{\mathrm{o}} \nabla \mathrm{T}^{4}\right)+\nabla\left(\mathrm{H}_{\mathrm{A}} \mathrm{F}_{\mathrm{A}}^{\vec{A}}\right)+ \\
\nabla\left(\mathrm{H}_{\mathrm{G}} \mathrm{F}_{\mathrm{G}}\right)=\mathrm{H}_{\mathrm{A}} \mathrm{q}_{\mathrm{A}}+\mathrm{H}_{\mathrm{G}} \mathrm{q}_{\mathrm{G}}+\dot{\mathrm{n}} \Delta \mathrm{H}_{\mathrm{H}}^{\mathrm{o}}
\end{array}
$$

For fluid flow in porous media, the aqueous and gas velocities are assumed to obey the multiphase Darcy's law in Equations (2.1), (2.2), (2.4) [5]:

$$
\begin{gathered}
\mathrm{F}_{\mathrm{A}}=-\mathrm{K}_{\mathrm{abs}} \frac{\mathrm{K}_{\mathrm{rA}} \rho_{\mathrm{A}}}{\mu_{\mathrm{A}}}\left(\nabla \mathrm{P}_{\mathrm{A}}-\rho_{\mathrm{A}} \mathrm{g}\right) \\
\mathrm{F}_{\mathrm{G}}^{\overrightarrow{ }}=-\mathrm{K}_{\mathrm{abs}}\left(1+\frac{\mathrm{b}}{\mathrm{P}_{\mathrm{G}}}\right) \frac{\mathrm{K}_{\mathrm{rG}} \rho_{\mathrm{G}}}{\mu_{\mathrm{G}}} \mathrm{X}_{\mathrm{G}}^{\mathrm{K}}\left(\nabla \mathrm{P}_{\mathrm{G}}-\rho_{\mathrm{G}} \mathrm{g}\right)
\end{gathered}
$$

In Equation (2.4), the enthalpies [5]:

$$
\begin{aligned}
& \mathrm{H}_{\mathrm{A}}=\mathrm{X}_{\mathrm{A}}^{\mathrm{w}} \mathrm{H}_{\mathrm{A}}^{\mathrm{w}}+\mathrm{X}_{\mathrm{A}}^{\mathrm{m}}\left(\mathrm{H}_{\mathrm{A}}^{\mathrm{m}}+\mathrm{H}_{\mathrm{sol}}^{\mathrm{m}}\right) \\
& \mathrm{H}_{\mathrm{G}}=\mathrm{X}_{\mathrm{G}}^{\mathrm{w}} \mathrm{H}_{\mathrm{G}}^{\mathrm{w}}+\mathrm{X}_{\mathrm{G}}^{\mathrm{m}} \mathrm{H}_{\mathrm{G}}^{\mathrm{m}}+\mathrm{H}_{\text {departure }} \\
& \mathrm{H}_{\mathrm{H}}=\mathrm{X}_{\mathrm{H}}^{\mathrm{w}} \mathrm{H}_{\mathrm{H}}^{\mathrm{W}}+\mathrm{X}_{\mathrm{H}}^{\mathrm{m}} \mathrm{H}_{\mathrm{H}}^{\mathrm{m}}+\Delta \mathrm{H}_{\mathrm{H}}^{0} \\
& \mathrm{H}_{\mathrm{I}}=\mathrm{H}_{\mathrm{I}}^{\mathrm{w}}+\Delta \mathrm{H}_{\mathrm{I}}^{0}
\end{aligned}
$$

Where A: aqueous phase; G: gas phase; I: ice phase; $\mathrm{H}$ : hydrate; $\varphi$ : porosity; $\rho_{\mathrm{R}}$ : rock density $\left[\mathrm{kg} \mathrm{m}^{-3}\right] ; \rho_{\beta}$ : density of phase $\beta(A, G, H, I)\left[\mathrm{kg} \mathrm{m}^{-3}\right] ; S_{\beta}$ : saturation of phase $\beta$ $(\mathrm{A}, \mathrm{G}, \mathrm{H}, \mathrm{I}) ; \mathrm{X}_{\beta}^{\kappa}$ : mass fraction of component $\kappa$ : w (water), $\mathrm{m}$ (methane),c (hydrate) in phase $\beta$ (A, G, H ,I) $[\mathrm{kg} / \mathrm{kg}] ; \mathrm{J}_{\mathrm{G}}{ }^{\kappa}$ the diffusive mass flux of component $\kappa$ in the gas phase $[\mathrm{kg}$ $\left.\mathrm{m}^{-2} \mathrm{~s}^{-1}\right] ; \mathrm{M}_{\text {weight }}^{\mathrm{m}}$ : molecular weight of $\mathrm{CH}_{4} ; \mathrm{M}_{\text {weight }}^{\mathrm{h}}$ : molecular weight of $\mathrm{CH}_{4}$ hydrate; $\mathrm{F}^{\kappa}$ : Darcy flux vector of component $\left[\mathrm{kg} \mathrm{m}^{-2} \mathrm{~s}^{-1}\right]$; $\mathrm{J}_{\beta}^{\kappa}$ :diffusion of component $\kappa$ in phase $\beta$ : $G ; q^{\kappa}$ : source/sink term of component $\kappa$ : $w$ (water), $\mathrm{m}$ (methane),c (hydrate) $\left[\mathrm{kg} \mathrm{m}^{-3} \mathrm{~s}^{-1}\right]$; t: time, second; $\mathrm{K}_{\mathrm{abs}}$ : rock instrinsic permeability $\left[\mathrm{m}^{2}\right] ; \mathrm{K}_{\mathrm{rA}}$ : relative permeability of the aqueous phase; $\mu_{\mathrm{A}}$ : viscosity of the aqueous phase $[\mathrm{Pa} \mathrm{s}] ; \mathrm{P}_{\beta}$ : Pressure of $\beta$ phase: $\mathrm{A}, \mathrm{G},[\mathrm{Pa}]$; $\mathrm{g}$ : gravitational accelaration vector $\left[\mathrm{m} \mathrm{s}^{-2}\right]$; b: Klinkenberg b-factor; $\mathrm{K}_{\mathrm{rG}}$ : relative permeability of the gaseous phase, $\mu_{\mathrm{G}}$ : viscosity of the gaseous phase $[\mathrm{Pa} \mathrm{s}] ; \mathrm{K}_{\mathrm{R}}$ : thermal conductivity of the rock $\left[\mathrm{W} \quad \mathrm{m}^{-1} \mathrm{~K}^{-1}\right] ; \mathrm{K}_{\beta}$ : thermal

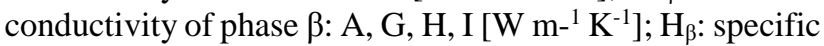
enthalpy of phase $\beta$ : A, G, H, I $\left[\mathrm{J} \mathrm{kg}^{-1}\right]$; f $\sigma$ : radiance emittance factor; $\sigma_{\mathrm{o}}$ : Stefan-Boltmann Constant [5.6687x10-8 $\left.\mathrm{J} \mathrm{m}^{-2} \mathrm{~K}^{-4}\right] ; \mathrm{U}_{\beta}$ : specific internal energy of phase $\beta[\mathrm{J} / \mathrm{kg}] ; \Delta \mathrm{H}_{\mathrm{H}}^{0}$ : latent heat of hydrate formation or dissociation $(\mathrm{J} \mathrm{kg}-1) ; \Delta \mathrm{H}_{\mathrm{I}}^{0}$ : latent heat of ice formation or dissociation $\left(\mathrm{J} \mathrm{kg}^{-1}\right)$.

During the numerical simulation, the mass balance, flow equations and heat balance equations are solved in a nonisothermal system because with hydrate formation or dissociation, the temperature of the system is not constant. Moreover, phases (hydrate, gas, aqueous, ice) change with hydrate formation or dissociation. This phase changes are tracked by using the primary switching method and with the changes of phases, the primary variables in the mass and heat equations also change. Primary variables for kinetic model are shown in Table 2. Finite difference method is used to solve differential equations implicitly. For every grids, the equations from Equation (2.1) to Equation (2.10) are solved for kinetic model [5].

Almost all of the numerical simulators in Table 1 are not free and some of them are private and only used in their research group. Therefore, it is important to write the codes of your own and make it freely available with the tutorials in details. For this purpose, initially, HEP software was written with Matlab to predict gas hydrate properties [3]. As seen from Equation (2.1) to (2.10), many properties of water, ice and $\mathrm{CH}_{4}$ such as mainly density, their dissolutions in different phases, viscosity, thermal conductivity, enthalpy and internal energy are essential in

\begin{tabular}{|c|c|c|c|c|c|}
\hline 离 & 营 & 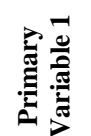 & 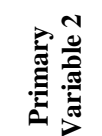 & 焉 & 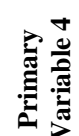 \\
\hline $\begin{array}{c}\text { 1-Phase: } \\
\text { Aqu }\end{array}$ & Aqu & $\mathrm{P}$ & X_m_A & S_hyd & $\mathrm{T}$ \\
\hline $\begin{array}{l}\text { 2-Phase: } \\
\text { AqG } \\
\text { 2-Phase: } \\
\text { AqH }\end{array}$ & $\begin{array}{l}\text { AqG } \\
\mathbf{A q H}\end{array}$ & $\begin{array}{c}\text { P_gas } \\
\mathrm{P}\end{array}$ & $\begin{array}{l}\text { S_aqu } \\
\text { S_aqu }\end{array}$ & $\begin{array}{l}\text { S_hyd } \\
\text { X_m_A }\end{array}$ & $\mathrm{T}$ \\
\hline $\begin{array}{c}\text { 3-Phase: } \\
\text { AGH } \\
\text { 3-Phase: } \\
\text { AIG }\end{array}$ & $\begin{array}{c}\text { AGH } \\
\text { AIG }\end{array}$ & $\begin{array}{l}\text { P_gas } \\
\text { P_gas }\end{array}$ & $\begin{array}{l}\text { S_aqu } \\
\text { S_aqu }\end{array}$ & $\begin{array}{l}\text { S_gas } \\
\text { S_hyd }\end{array}$ & $\begin{array}{c}\mathrm{T} \\
\text { S_gas }\end{array}$ \\
\hline $\begin{array}{l}\text { Quadruple } \\
\text { Point: QuP }\end{array}$ & QuP & $P_{\text {_gas }}$ & S_aqu & S_gas & S_ice \\
\hline
\end{tabular}
order to run gas production simulations for gas hydrate reservoirs. Only $\mathrm{CH}_{4}$ is selected as guest molecules in gas hydrates because in nature, biogenic $\mathrm{CH}_{4}$ hydrate is common [1-3]. For this reason, waterprop.m, iceprop.m and gasprop.m codes were written with Matlab to predict these parameters.

Table 2. Primary Variables in Kinetic Hydrate Simulations without Inhibitor [5]*.

* Where the possible primary variables are: $\mathrm{P}$, pressure [Pa]; $\mathrm{P} \_$gas, gas pressure [Pa]; T, temperature [C]; $\mathrm{X} \_\mathrm{m} \_\mathrm{A}$, mass fraction of $\mathrm{CH}_{4}$ dissolved in the aqueous phase; $\mathrm{Y}_{-} \mathrm{m} \_\mathrm{G}$, mass fraction of $\mathrm{CH}_{4}$ dissolved in the gas phase; S_aqu, liquid saturation; S_gas, gas saturation; S_hyd, hydrate saturation; X_i_A, mass fraction of inhibitor dissolved in the aqueous phase. If the system including an inhibitor, the variables are updated as: $\mathrm{X} \_\mathrm{iA}$ becomes the $4^{\text {th }}$ primary variable, and the $4^{\text {th }}$ primary variable (as listed in Table 2 ) becomes the $5^{\text {th }}$ primary variable 


\section{Results and Discussion}

\subsection{Prediction of Water Properties}

During gas hydrate production simulations, water properties at different pressure and temperature values are essential. Even though some of water properties such as density and viscosity were assumed constant in some of the gas hydrate simulation studies [4], water properties change with temperature and pressure. For accurate simulations, these changes should be in consideration. In order to account for the changes in water properties such as density of water or aqueous phase (if it includes dissolved gas), specific internal energy, specific isobaric heat capacity, specific enthalpy, thermal conductivity, thermal diffusivity, surface tension and vapor pressure at different temperature and pressure, waterprop.m code was written in Matlab. To analyze the reliability of this code, the calculated data with waterprop.m were compared with those data in National Institute of Standards and Technology (NIST) [6]. If $\mathrm{CH}_{4}$ dissolved in water, it changes water properties such as density and viscosity. By entering dissolved gas composition and $\mathrm{CH}_{4}$ gas density, the properties of aqueous phase are easily calculated with waterprop.m.

In a project of the DOE (Department of Energy, USA)/NETL (National Energy Technology Laboratory), the code comparison studies were conducted for seven case problems of gas hydrate simulations by five different reservoir simulators: CMG STARS, HydrateResSim, MH21 HYDRES, STOMP-HYD, and TOUGH+HYDRATE. For instance, a $10 \mathrm{~m}$ hydrate zone $(80 \%$ gas hydrate saturation) in bounded vertically by two $25 \mathrm{~m}$ shale zones (the length and height of the domain is $1000 \mathrm{~m} \times 60 \mathrm{~m}$ ) were selected as a case study. Then, gas production for this case was simulated with different size of grids by depressurization method [4]. Figure 3 shows the cumulative gas and water production for the selected case problem.
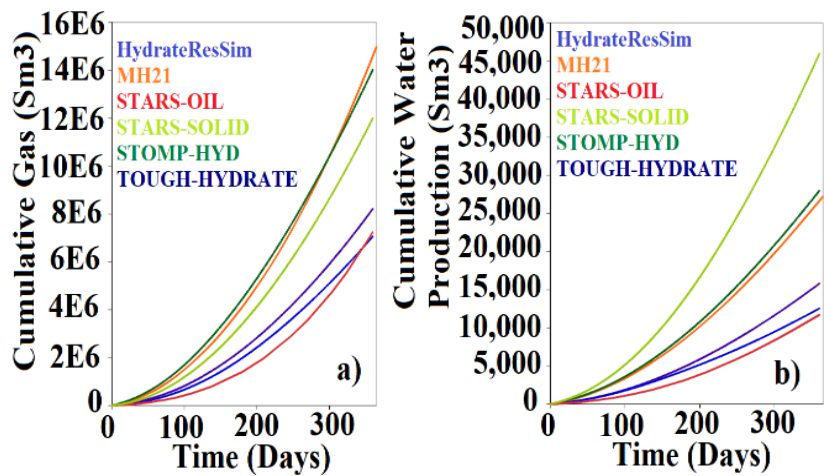

Figure 3. a) Cumulative Gas Production b) Cumulative Water Production [4].
As seen in Figure 3, the simulation results are quite different because every gas hydrate reservoir simulator has its own numerical method, assumptions, relative permeability formulas, gas properties, water properties and ice properties. Unfortunately, the tutorials of these simulators are not very informative. Hence, in this study and Merey and Sinayuc [3], it is aimed to describe all the methods used one by one and propose a new gas hydrate simulator to predict gas production by especially depressurization because it is the most commonly preferred gas production method [1]. Thus, the codes predicting water properties, $\mathrm{CH}_{4}$ properties and ice properties are proposed in this study.

As shown in Equations (2.1) to (2.10), many properties of water should be calculated at different temperature and pressure values for each time step of numerical gas production simulation from gas hydrates. These water properties are:

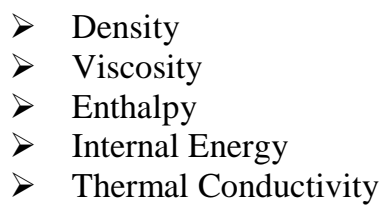

Figure 4 shows the algorithm of waterprop.m code written in this study in Matlab [7-10] Mainly, in Equations (2.1), (2.2), (2.4) and (2.5), water density is essential at different temperatures and pressures. In order provide water density to these equations, the formulas of IAPWS-IF97 [7] were used and these formulas are valid when pressure is less than $100 \mathrm{MPa}$ and temperature is between $273.15 \mathrm{~K}$ and 1073.15 K. Similarly, the formulas proposed in IAPWS-IF97 [7] were used to calculate internal energy and enthalpy. The temperature and pressure conditions of marine gas hydrate reservoirs are in the pressure-temperature ranges of the formulas of IAPWS-IF97 [1, 3].

Gas production from gas hydrates is non-isothermal so the prediction of energy parameters is quite important for accurate numerical studies as seen in Equation (2.4) and Equations (2.7) to (2.10). During gas production with gas hydrate dissociation, water and gas exist together and multiphase flow occurs. Especially for the calculation of flux parameters in Equations (2.5) and (2.6), viscosity should be estimated at different temperature and pressure values. By using the method of Sengers and Parsi [8], water viscosity is predicted at different pressures and temperatures. Thermal conductivities are also important as shown in Equation (2.4) and it is predicted in waterprop.m by using the method of IAPWS [9]. 
Celal Bayar University Journal of Science

Volume 14, Issue 2, p 177-186

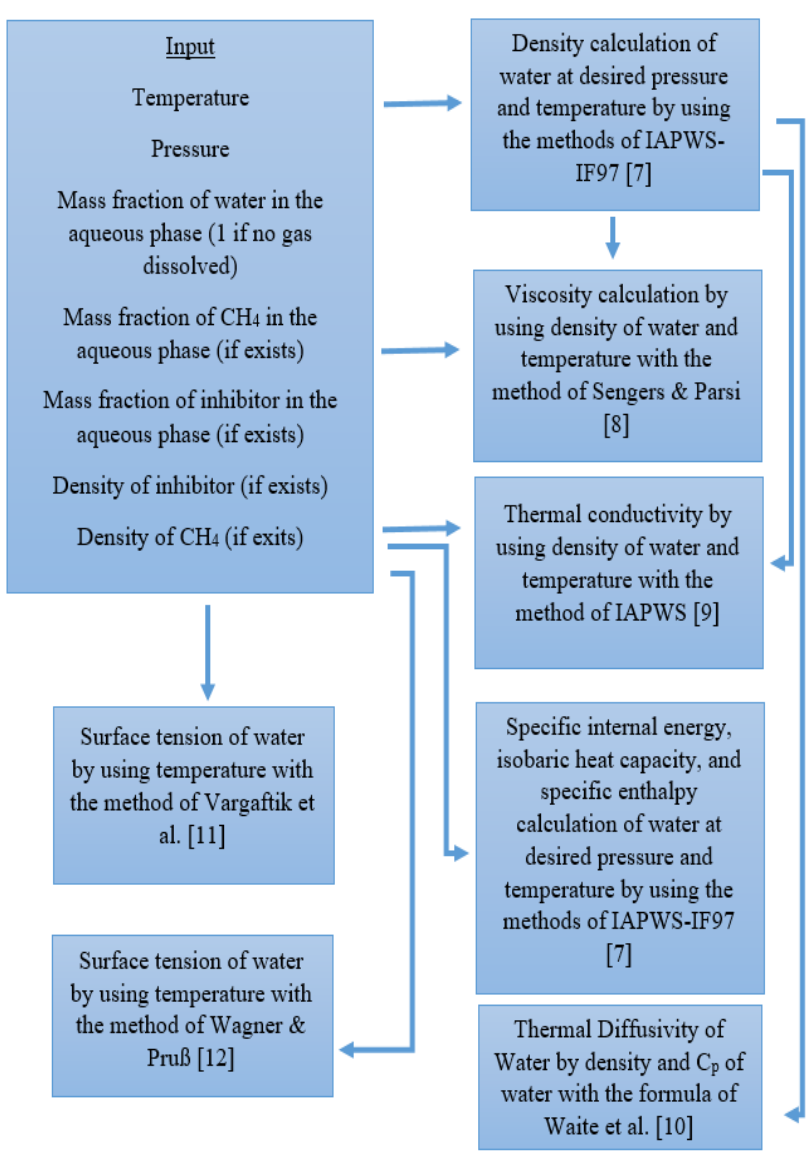

Figure 4. Algorithm of waterprop.m code.

The water properties calculated by waterprop.m and NIST [6] at $5^{\circ} \mathrm{C}, 10^{\circ} \mathrm{C}, 15^{\circ} \mathrm{C}, 20^{\circ} \mathrm{C}$ and $25^{\circ} \mathrm{C}$ when pressure is between 0 and $24 \mathrm{MPa}$ are shown in Figure 5. The reason of the selection of these temperature ranges $\left(5\right.$ to $\left.25^{\circ} \mathrm{C}\right)$ and pressure ranges ( 0 to $24 \mathrm{MPa}$ ) is that the temperature and pressure of gas hydrates in nature are within these ranges $[1,3]$. During gas production from gas hydrate reservoirs, both temperature and pressure vary. For example, while applying depressurization method, pressure and temperature decrease. The reason of temperature reduction is due to the endothermic dissociation of gas hydrates. For this reason, for numerical simulators, the prediction of gas and water properties at different pressure and temperature values is quite important. The range selected in this study is appropriate for marine gas hydrate reservoirs.

As seen in Figure 5, there are good agreements between density, viscosity enthalpy, internal energy and thermal conductivity of water calculated by NIST [6] and waterprop.m. Moreover, $\mathrm{R}^{2}$ error analysis were done between these values estimated with NIST [6] and waterprop.m. Table 3 lists these $\mathrm{R}^{2}$ values and it is obvious that the accuracies of the results are higher than $99 \%\left(\mathrm{R}^{2}\right)$.
Table 3. Error Analysis between NIST [6] and waterprop.m (Figure 5).

\begin{tabular}{|c|c|c|c|c|c|}
\hline \multirow[b]{2}{*}{ Condition } & \multicolumn{5}{|c|}{$\mathbf{R}^{2}(\%)$} \\
\hline & 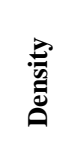 & 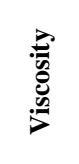 & 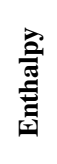 & 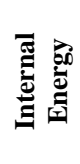 & 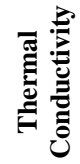 \\
\hline At $25^{\circ} \mathrm{C}$ & 99.99 & 100 & 100 & 99.99 & 99.04 \\
\hline At $20^{\circ} \mathrm{C}$ & 100 & 100 & 100 & 100 & 99.07 \\
\hline At $15^{\circ} \mathrm{C}$ & 100 & 99.99 & 100 & 100 & 99.41 \\
\hline At $10^{\circ} \mathrm{C}$ & 99.99 & 100 & 100 & 100 & 99.28 \\
\hline At $5^{\circ} \mathrm{C}$ & 99.99 & 100 & 100 & 100 & 99.36 \\
\hline
\end{tabular}
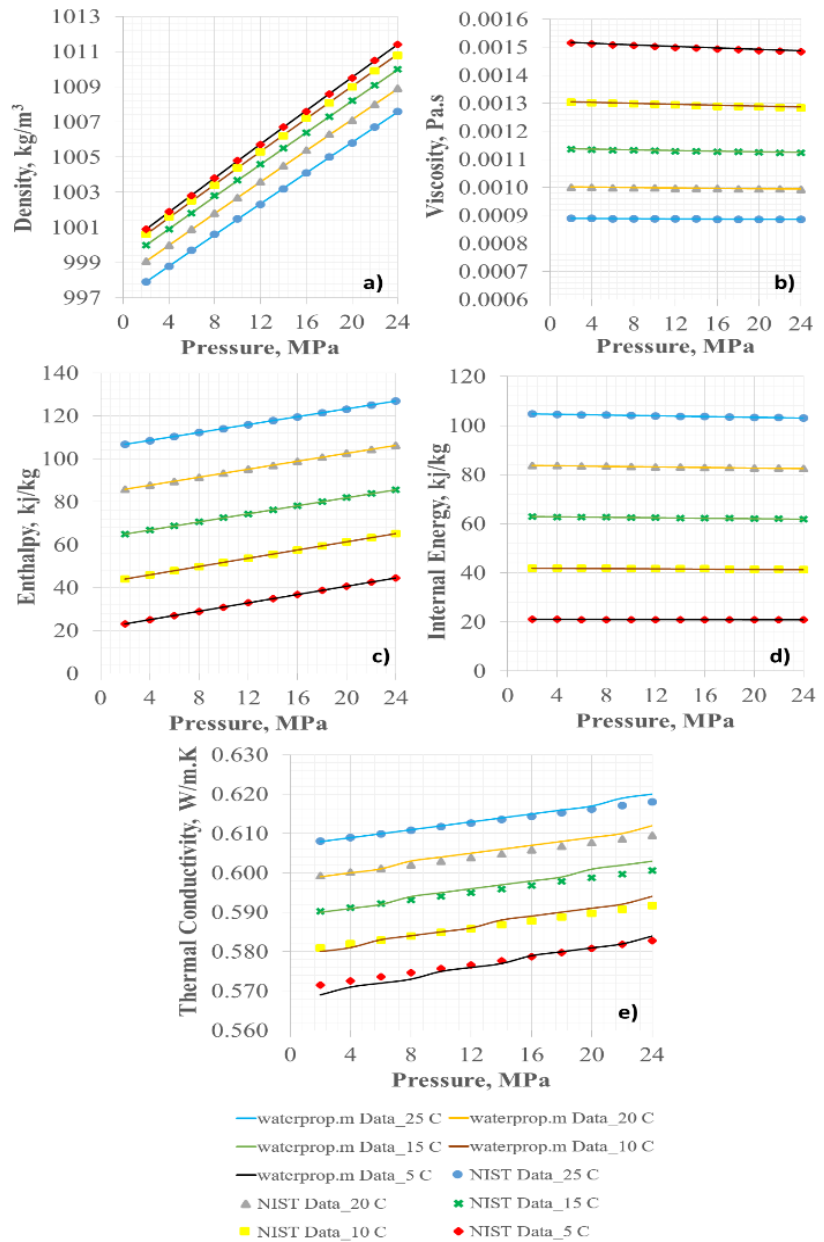

Figure 5. Variations of (a) density (b) viscosity c) enthalpy d) internal energy (e) thermal conductivity of water with increasing pressure and temperature. 
For this reason, waterprop.m has ability to estimate water properties and these values can be used during numerical gas production from gas hydrates. As seen in Figure 5-a, as pressure increases or temperature decreases, the density of water increases. This is the expected behavior of water molecules. Figure 5-b indicates the viscosity of water varying with pressure and temperature. As expected, the viscosity of water decreases with increasing temperature but the effect of pressure on the viscosity of water is almost negligible. The enthalpy, internal energy and thermal conductivity of water increases with increasing pressure and increasing temperature as seen in Figure 5-c, Figure 5$\mathrm{d}$ and Figure 5-e, respectively. The calculated data with waterprop.m and NIST data fit very well as indicated in Figure 5 so this shows the reliability of waterprop.m code.

\subsection{Prediction of $\mathrm{CH}_{4}$ Properties}

While simulating gas production from gas hydrates in porous sediments, different phases can appear and disappear. For example, Table 2 lists the possible phases in HydrateResSim numerical simulator. Aqueous (Aqu), Aqueous and Gas $(\mathrm{AqG})$, Aqueous and Hydrate $(\mathrm{AqH})$, Aqueous, Hydrate and Gas (AGH), Aqueous, Ice and Gas (AIG), and 4 phases (Aqueous, Ice, Gas, Hydrate, QuP) might occur in porous sediments [5]. Hence, the estimation of gas $\left(\mathrm{CH}_{4}\right)$ properties at different temperature and pressure values is crucial for numerical simulation at each time step. Most of gas hydrates in nature include approximately $100 \%$ of $\mathrm{CH}_{4}$ [1] so in this study, it was aimed to calculate only $\mathrm{CH}_{4}$ properties instead of calculating the properties of other gases such $\mathrm{C}_{2} \mathrm{H}_{6}$ and $\mathrm{C}_{3} \mathrm{H}_{8}$, etc. Simulation of gas mixtures in gas hydrates increases the run time therefore most of the simulators only predict gas production from $\mathrm{CH}_{4}$ hydrates [4]. In order to estimate $\mathrm{CH}_{4}$ properties at different temperature and pressure conditions, gasprop.m Matlab code was written in this study. As seen in Equations (2.1) to (2.10), many properties of $\mathrm{CH}_{4}$ should be estimated at different temperatures and pressures at each time step of numerical gas production simulation from gas hydrates. These $\mathrm{CH}_{4}$ properties are [10-18]:

$\begin{array}{ll}> & \text { Density } \\ > & \text { Viscosity } \\ > & \text { Enthalpy } \\ > & \text { Internal Energy } \\ > & \text { Thermal Conductivity } \\ > & \text { Gas heat capacity }(\mathrm{Cp}) \\ > & \text { Solubility in water }\end{array}$

Figure 6 shows the algorithm of gasprop.m code written in this study in Matlab [10-18]. $\mathrm{CH}_{4}$ density is quite important as in mainly Equations (2.1), (2.2), (2.4), and (2.5), which is a function of pressure and temperature. Modified PengRobinson Equations of States (EOS) was chosen to calculate $\mathrm{CH}_{4}$ density and it is valid in wide range of pressure and temperature values. As well as the density of $\mathrm{CH}_{4}$, the viscosity of $\mathrm{CH}_{4}$ is an important factor determining gas flux in the pores (Equation (2.6)) while producing gas from gas hydrates. In gasprop.m code, the method of Hanley et al. [13] for $\mathrm{CH}_{4}$ viscosity calculation at different pressures and temperatures was preferred in this study. Different from conventional oil and gas reservoirs, gas hydrates are sensitive to temperature changes because its dissociation is endothermic and its formation is exothermic [2]. The energy parameters should be estimated and they are mostly function of pressure and temperature. For this purpose, the enthalpy and internal energy of $\mathrm{CH}_{4}$ are calculated with the formulas proposed by Kylie [18] in gasprop.m Matlab code. The formulas of Hanley et al. [13] and Younglove \& Elly [14] were integrated and used in gasprop.m to calculate thermal conductivity. Before using gasprop.m in numerical simulations, it is important to prove the reliability of this code. NIST (National Institute of Standards and Technology) [6] is a viable online program to calculate $\mathrm{CH}_{4}$ properties as a function of pressure and temperature.

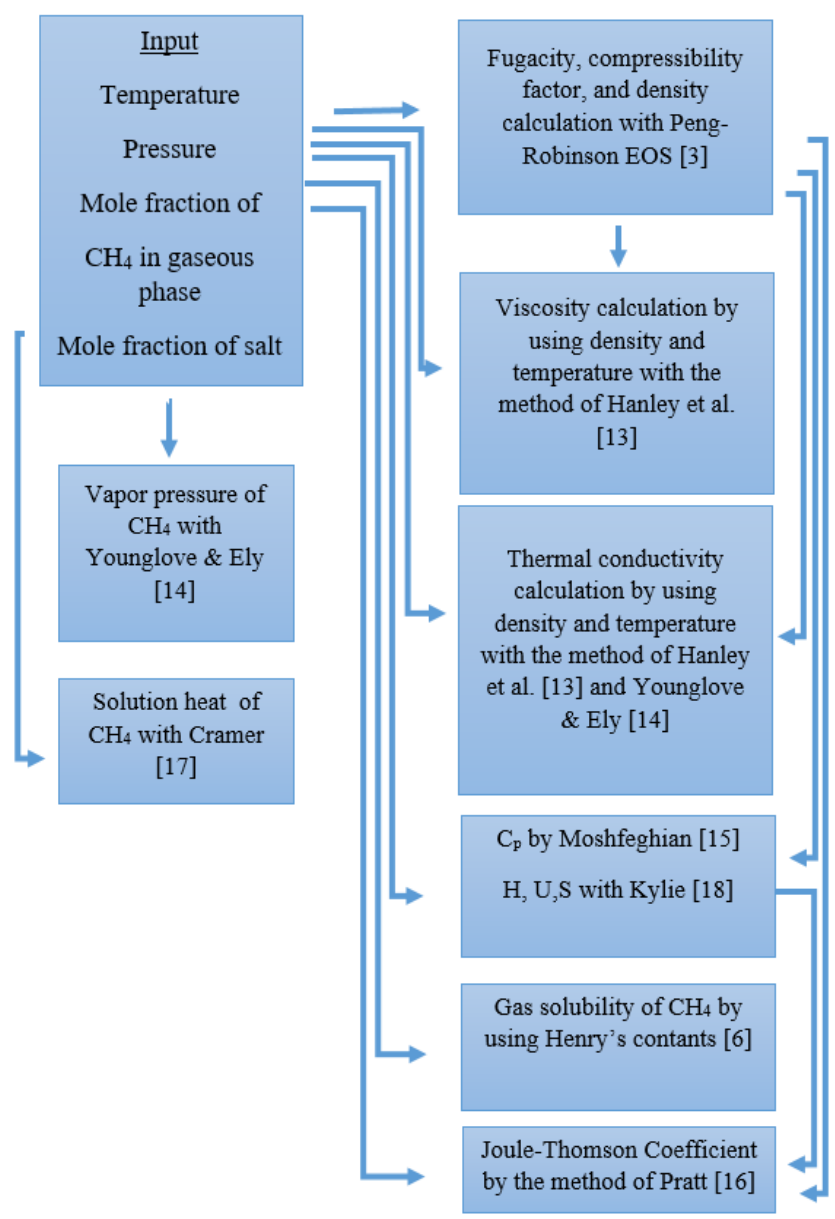

Figure 6. Algorithm of gasprop.m code. 
In this study, $\mathrm{CH}_{4}$ properties such as density, viscosity, thermal conductivity, enthalpy and internal energy estimated by NIST [6] and gasprop.m were compared in this study and the comparisons are shown in Figure 7. In Figure 7-a, Figure 7-b, Figure 7-c, Figure 7-d and Figure 7$\mathrm{e}$, the density, viscosity, enthalpy, internal energy and thermal conductivity of $\mathrm{CH}_{4}$ calculated by gasprop.m and NIST [6] are shown respectively at $5^{\circ} \mathrm{C}, 10^{\circ} \mathrm{C}, 15^{\circ} \mathrm{C}, 20^{\circ} \mathrm{C}$ and $25^{\circ} \mathrm{C}$ with varying pressure from 0 to $24 \mathrm{MPa}$. These temperature and pressure conditions are commonly observed in marine gas hydrate reservoirs [1,3] so these values were selected to test the reliability of gasprop.m.

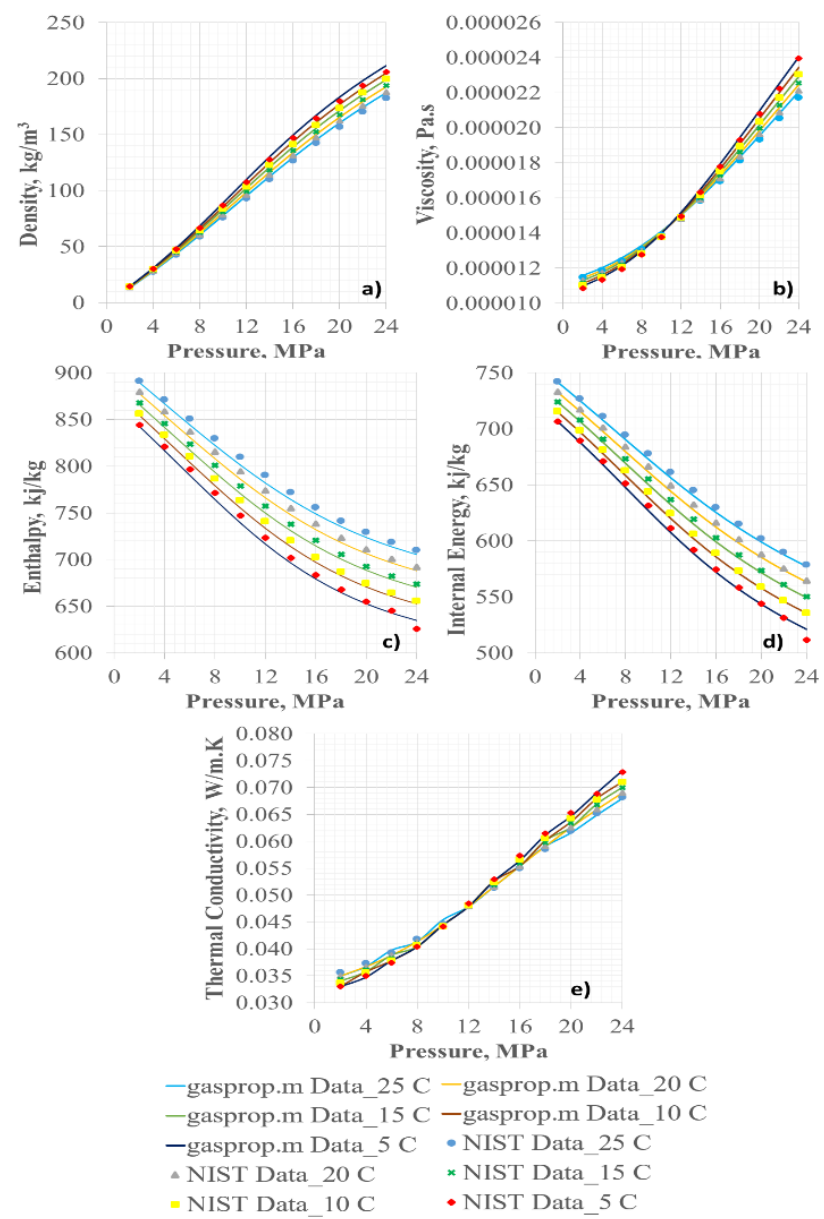

Figure 7. Variations of (a) density (b) viscosity (c) enthalpy (d) internal energy (e) thermal conductivity of $\mathrm{CH}_{4}$ with increasing pressure and temperature.

As shown in Figure 7, there are good agreements between the density, viscosity enthalpy, internal energy and thermal conductivity of $\mathrm{CH}_{4}$ calculated by NIST [6]. Moreover, $\mathrm{R}^{2}$ error analysis were done between these values estimated with NIST [6] and gasprop.m. Table 4 lists these $\mathrm{R}^{2}$ values and it is obvious that the accuracies of the results are higher than $99 \%\left(\mathrm{R}^{2}\right)$. Therefore, gasprop.m has ability to estimate $\mathrm{CH}_{4}$ properties and these values can be used during numerical gas production from gas hydrates.

Table 4. Error Analysis between NIST [6] and gasprop.m (Figure 7).

\begin{tabular}{|c|c|c|c|c|c|}
\hline \multirow[b]{2}{*}{ Condition } & \multicolumn{5}{|c|}{$\mathbf{R}^{2}(\%)$} \\
\hline & 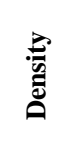 & 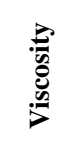 & 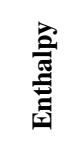 & 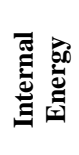 & 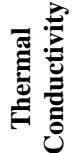 \\
\hline At $25^{\circ} \mathrm{C}$ & 100 & 99.99 & 99.84 & 99.87 & 99.74 \\
\hline At $20^{\circ} \mathrm{C}$ & 100 & 99.98 & 99.85 & 99.88 & 100 \\
\hline At $15^{\circ} \mathrm{C}$ & 100 & 99.98 & 99.85 & 99.88 & 99.81 \\
\hline At $10^{\circ} \mathrm{C}$ & 99.99 & 99.97 & 99.85 & 99.88 & 99.83 \\
\hline At $5^{\circ} \mathrm{C}$ & 100 & 99.97 & 99.49 & 99.54 & 99.87 \\
\hline
\end{tabular}

As seen in Figure 7-a, as pressure increases or temperature decreases, the density of $\mathrm{CH}_{4}$ increases. The effect of pressure on gas properties is high. Figure 7-b indicates the viscosity of $\mathrm{CH}_{4}$ varying with pressure and temperature. As expected, the viscosity of $\mathrm{CH}_{4}$ increases with increasing pressure. The enthalpy and internal energy of $\mathrm{CH}_{4}$ decreases with increasing pressure and decreasing temperature as seen in Figure 7-c and Figure 7-d. The calculation of thermal conductivity of all fluids in the porous media is quite important for numerical gas production simulations from gas hydrate reservoirs since heat transfer is dominant in these systems. Therefore, by using gasprop.m, the thermal conductivity values of $\mathrm{CH}_{4}$ were calculated and compared with NIST data in Figure 7e. Compared to temperature, the effect of pressure on $\mathrm{CH}_{4}$ thermal conductivity is very high. The calculated data with gasprop.m and NIST data fit very well in Figure 7 so this indicates the reliability of gasprop.m.

\subsection{Prediction of Ice Properties}

Mostly gas hydrates in nature are stable at temperatures above $0^{\circ} \mathrm{C}$ (freezing point of water) and $99 \%$ of $\mathrm{CH}_{4}$ hydrates are thought to exist in marine sediments $[1,2]$. However, even the temperature of $\mathrm{CH}_{4}$ hydrate reservoir is above $0^{\circ} \mathrm{C}$, the reservoir temperature decreases below $0^{\circ} \mathrm{C}$ with endothermic dissociation of gas hydrates and ice forms inside the pores. In some studies, the exothermic ice formation adds additional heat to the reservoir and increases gas production but in other studies [3, 5], ice plugs the pores and decreases gas production. Therefore, ice properties mainly, density, thermal conductivity, specific enthalpy and specific internal energy should be calculated at different pressure and temperature values. For this purpose, iceprop.m Matlab code was developed in this study to be used during the gas hydrate simulations [19, 20]. Figure 8 illustrates the algorithm of iceprop.m Matlab code. 
Celal Bayar University Journal of Science

Volume 14, Issue 2, p 177-186

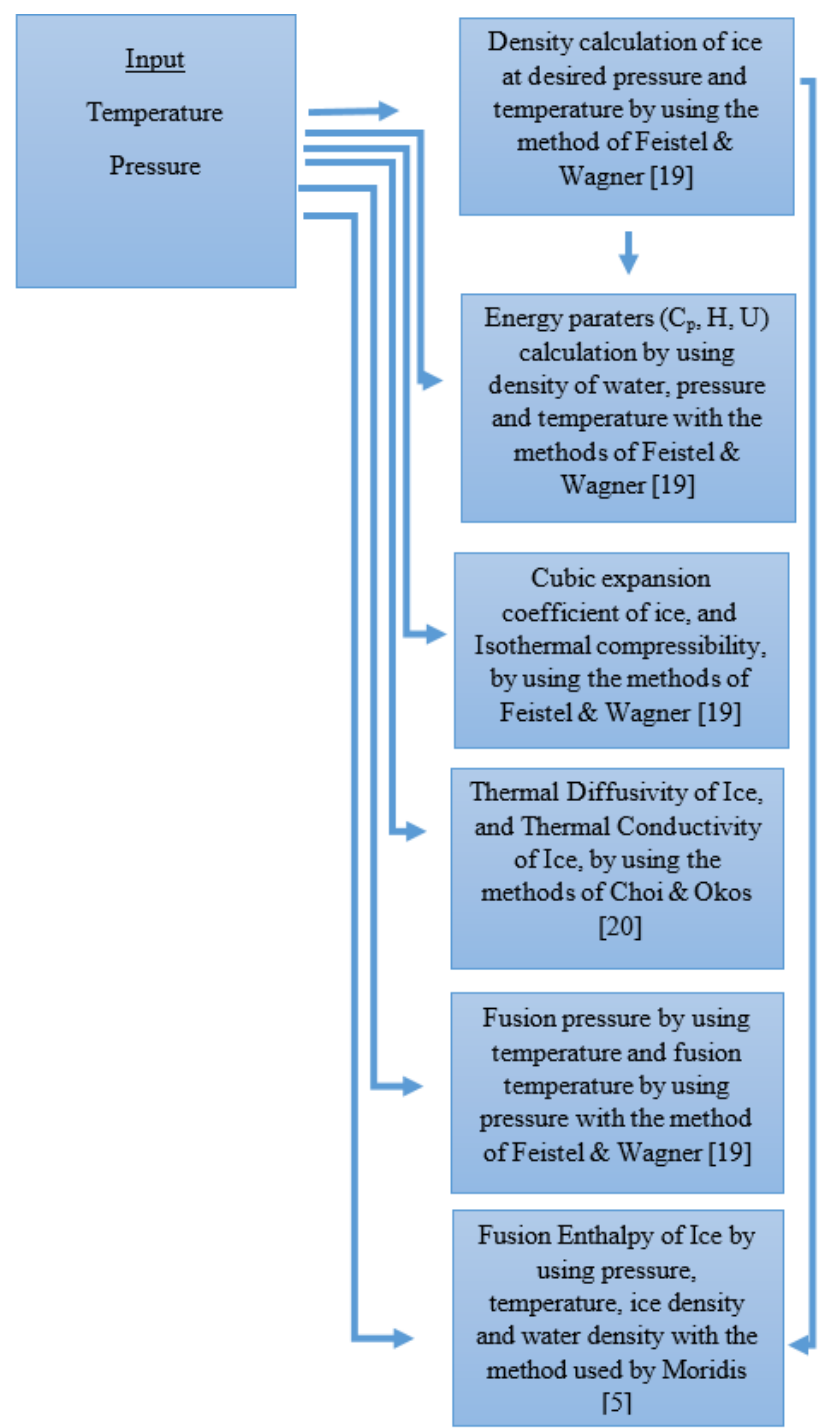

Figure 8. Algorithm of iceprop.m code.

Ice is in solid form so it is assumed stable in the pores and flux terms in Equations (2.5) and (2.6) are only valid for aqueous and gaseous phase flows. As seen in Equation (5.1), ice saturation decreases effective permeability and effective porosity. Thus, during numerical simulation, the determination of ice properties accurately is essential.

$$
K=K_{o}\left(1-S_{h}-S_{i}\right)^{N}
$$

Where K: Effective permeability; $\mathrm{K}_{\mathrm{o}}$ : Absolute permeability; $\mathrm{S}_{\mathrm{h}}$ : gas hydrate saturation; $\mathrm{S}_{\mathrm{i}}$ : ice saturation; $\mathrm{N}$ : fitting parameter between 2 and 15 depending on gas hydrate morphology in the pores [1]

Feistel and Wagner [19] proposed a set of formulas to estimate ice properties (ice density, specific enthalpy and specific internal energy of ice). These methods were used in iceprop.m code. For the calculation of thermal conductivity of ice, the method of Choi and Okos was chosen [20]. The results at different pressures and temperatures at $-2^{\circ} \mathrm{C},-5^{\circ} \mathrm{C}$, and $-10^{\circ} \mathrm{C}$ and $0-24 \mathrm{MPa}$ were shown in Figure 9. Online program of NIST (National Institute of Standards and Technology) [6] cannot predict ice properties at different temperature and pressure values so iceprop.m data were not compared with it. However, Feistel and Wagner [19] and Choi and Okos [20] obtained good results with their models therefore their methods were used in iceprop.m. Hence, iceprop.m code is aimed to be used in the numerical study of gas production from gas hydrates if ice exists in the pores.

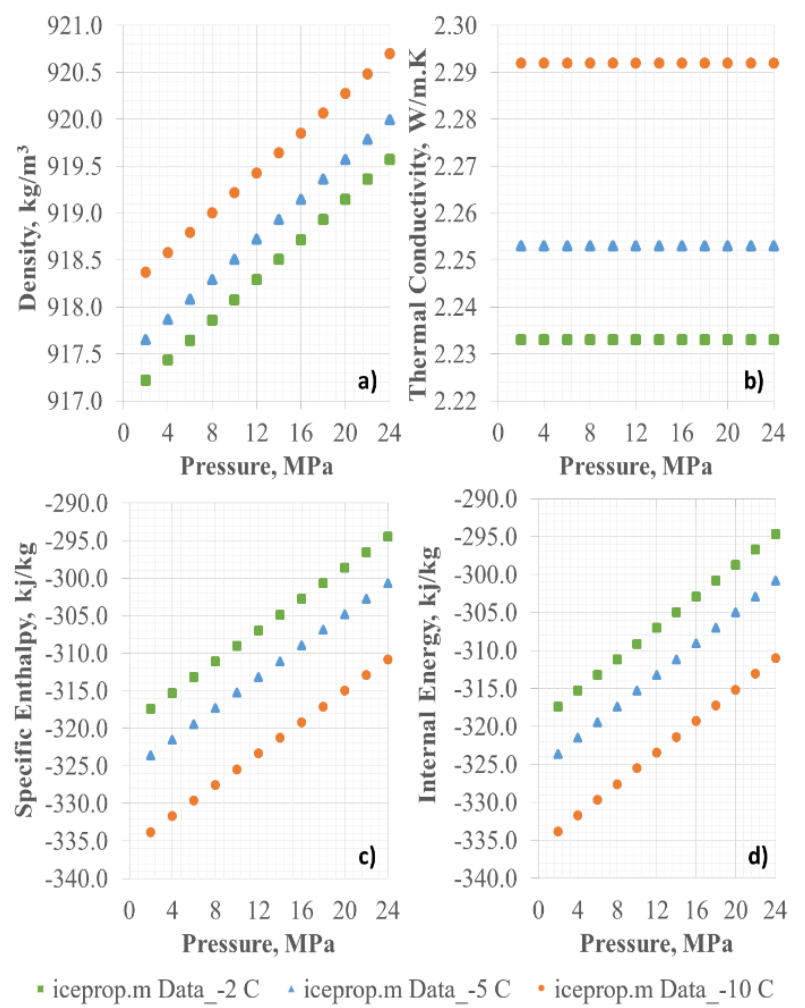

Figure 9. Variations of (a) density and (b) thermal conductivity (c) enthalpy (d) internal energy of ice with increasing pressure and temperature.

\section{Conclusion}

Numerical simulation of gas production from gas hydrate reservoirs requires non-isothermal multiphase calculations at each time step. This is because during gas production both pressure and temperature values in the system changes quickly. For this reason, the prediction of water properties, $\mathrm{CH}_{4}$ properties (density, viscosity, enthalpy, internal energy, thermal conductivity), and ice properties (density, enthalpy, internal energy, thermal conductivity) at different pressure ( 0 to $24 \mathrm{MPa}$ ) and temperature $\left(5\right.$ to $25^{\circ} \mathrm{C}$ ) values is quite important. These pressure and temperature ranges 
were selected according to the ranges of natural gas hydrate reservoirs in marine environment.

In this study, the Matlab codes written: waterprop.m and gasprop.m to predict water and $\mathrm{CH}_{4}$ properties, which are necessary to simulate gas production from gas hydrate reservoirs. These codes will be the core of future numerical gas hydrate codes planned to be developed. For this reason, it was important to prove the reliability of the Matlab codes written in this study. The reliability of these codes was proved by comparing with NIST [6] data. Due to the possibility of ice formation in the pores during gas production especially with depressurization method, ice properties (density, enthalpy, internal energy and thermal conductivity) are predicted with iceprop.m Matlab code written in this study.

In this study, gas hydrates in permafrost region were ignored because it is known that most of gas hydrates in the world are located in marine environment. Therefore, waterprop.m, gasprop.m and iceprop.m can be used for marine gas hydrate reservoirs instead of permafrost gas hydrate reservoirs.

\section{Acknowledgements}

The author declares that there is no conflict of interest.

\section{References}

1. Max, MD, Johnson, AH, Exploration and production of oceanic natural gas hydrate; Springer Nature: Switzerland, 2016.

2. Koh, CA, Sloan, ED, Sum, AK, Unconventional energy sources: gas hydrates. In: Ginley DS, Cahen D (ed) Fundamentals of materials for energy and environmental sustainability, Cambridge University Press and Materials Research Society, Cambridge, 2012.

3. Merey, S, Sinayuc, C, New software that predicts hydrate properties and its use in gas hydrate studies, Journal of Chemical \& Engineering Data, 2016, 61 (5), 1930-1951.

4. Gaddipati, M, Code comparison of methane hydrate reservoir simulators using CMG STAR, MSc thesis, West Virginia University, USA, 2008.

5. Moridis, GJ, Kowalsky, MB, Pruess, K, HydrateResSim User's Manual: A numerical simulator for modeling the behavior of hydrates in geologic media, Earth Sciences Division, Lawrence Berkeley National Laboratory, Berkeley, CA, 2005.

6. NIST, Thermophysical Properties of Fluid Systems. accessed on 27 September, 2016, http:// webbook.nist.gov/chemistry/fluid/ (accessed 27.09.2016)

7. IAPWS, Revised Release on the IAPWS Industrial Formulation 1997 for the Thermodynamic Properties of Water and Steam, The International Association for the Properties of Water and Steam Lucerne, Switzerland, August, 2007.
8. Sengers, JV, Parsi, BK, Representative equations for the viscosity of water sub- stance, The Journal of Physical and Chemical Reference Data, 1984, 13, 185-205.

9. IAPWS, Release on the IAPWS Formulation 2011 for the Thermal Conductivity of Ordinary Water Substance, The International Association for the Properties of Water and Steam, Czech Republic, September, 2011.

10. Waite, WF, Stern, L, Kirby, SH, Winters, WJ, Mason, DH, Simultaneous determination of thermal conductivity, thermal diffusivity and specific heat in sI methane hydrate, Geophysical Journal International, 2007, 169(2), 767-774.

11. Vargaftik, NB, Volkov, BN, Voljak, LD, International Tables of the Surface Tension of Water, The Journal of Physical and Chemical Reference Data, 1983, 12, 817-820.

12. Wagner, W, Pruß, A, The IAPWS formulation 1995 for the thermodynamic properties of ordinary water substance for general and scientific use, The Journal of Physical and Chemical Reference Data, 2002, 31, 387-535.

13. Hanley, HJM, Haynes, WM, McCarty, RD, The viscosity and thermal conductivity coefficients for dense gaseous and liquid methane, The Journal of Physical and Chemical Reference Data, 1977, 6, 2, 597 616.

14. Younglove, BA, Ely, JF, Thermophysical properties of fluids. II. Methane, ethane, propane, isobutane, and normal butane, The Journal of Physical and Chemical Reference Data, 1987, 16, 4, 577-798.

15. Moshfeghian, M, Variation of Natural Gas Heat Capacity with Temperature, Pressure, and Relative Density, Oil Gas Journal, 2011, 109,40 .

16. Pratt, RM, Thermodynamic Properties Involving Derivatives Using the Peng-Robinson Equation of State, Chemical Engineering Education, 2001, 35, 112-115.

17. Cramer, $\mathrm{SD}$, The solubility of methane, carbon dioxide and oxygen in brines from 0 C to 300 C, U.S. Bureau of Mines, Report No. 1982, 8706,16

18. Kyle, BG, Chemical and process thermodynamics; 3rd edition, Prentice Hall PTR: New Delhi, 1999.

19. Feistel, R, Wagner, WA, A new equation of state for $\mathrm{H} 2 \mathrm{O}$ ice $\mathrm{Ih}$, The Journal of Physical and Chemical Reference Data, 2006, 35, 1021-

20. Choi, Y, Okos, MR, Effects of temperature and composition on the thermal properties of foods. In: LeMaguer, M, Jelen, P (ed), Food Engineering and Process Applications; Elsevier Applied Science: London, 1986. 